Review began 12/21/2021 Review ended 01/18/2022 Published 01/21/2022

(๑) Copyright 2022

Aljehani et al. This is an open access article distributed under the terms of the Creative Commons Attribution License CC-BY 4.0., which permits unrestricted use, distribution, and reproduction in any medium, provided the original author and source are credited.

\section{Survey of Primary Care Physicians' Screening and Treatment Practices for Prediabetes in Saudi Arabia}

\author{
Faisal Aljehani ${ }^{1}$, Abdullah Alsulaiman ${ }^{1}$, Abdulrahim Alqarni ${ }^{1}$, Fahad Almutairi ${ }^{1}$, May Samkari ${ }^{2}$ \\ 1. College of Medicine, Department of Internal Medicine, University of Jeddah, Jeddah, SAU 2. Health Program and \\ Chronic Disease Adminstration, Public Health Administration at Saudi Ministry of Health, Jeddah, SAU
}

Corresponding author: Faisal Aljehani, faaljehani1@uj.edu.sa

\section{Abstract \\ Background}

Prediabetes is defined as a condition in which glucose levels do not fulfill the criteria for type 2 diabetes mellitus (T2DM), indicating that the patient is at an increased risk of developing T2DM. The risk of developing T2DM can be decreased by adequately managing prediabetes. This study aimed to assess screening and therapeutic approaches to prediabetes among primary care physicians in Saudi Arabia because there is little contemporary data available on this topic.

\section{Methodology}

A cross-sectional study was performed among primary care physicians in Saudi Arabia. The participants completed a validated online survey questionnaire via Google Forms. Data collected included participants' demographic information, knowledge of T2DM risk factors, and opinions and beliefs on prediabetes management.

\section{Results}

In total, 155 primary care physicians responded to the questionnaire; $51 \%$ were male, $18.7 \%$ worked in Riyadh City, and $81.3 \%$ specialized in family medicine. Most study respondents (71.9\%) were residents, and $64.5 \%$ worked for the Ministry of Health. Overall, $93.5 \%$ of the respondents had completed part of their postgraduate training in Saudi Arabia. Moreover, 27.7\% of the respondents were aware of all nine risk factors associated with T2DM. The correct fasting glucose and hemoglobin A1c ranges for the diagnosis of prediabetes were identified by $50 \%$ and $43.6 \%$ of participants, respectively. Most respondents believed lifestyle modification and metformin to be the most effective management approaches to prediabetes, whereas lack of motivation toward lifestyle changes was deemed to be a major barrier.

\section{Conclusions}

We found significant gaps in primary care physicians' knowledge regarding prediabetes in Saudi Arabia, contributing to underscreening of the condition and undertreatment. Identifying these gaps is essential for focussing educational endeavors toward primary care physicians.

Categories: Endocrinology/Diabetes/Metabolism, Family/General Practice, Internal Medicine Keywords: primary care, diabetes, risk factors, survey research, knowledge

\section{Introduction}

According to the American Diabetes Association's (ADA) guidelines, prediabetes refers to glucose levels that do not fulfill the criteria for type 2 diabetes mellitus (T2DM). Individuals with prediabetes have an increased risk of T2DM onset, cardiovascular pathologies, and all-cause mortality [1,2]. In addition, prediabetes increases the risk of developing T2DM and correlates with an annual progression of 5-10\% toward T2DM [3].

Prediabetes is associated with impaired fasting glucose and/or impaired glucose tolerance. Recent data indicate that more than one-third of adults in affluent countries have prediabetes [4]. Fasting glucose concentrations of 100-125 mg/dL, hemoglobin A1c (HbA1c) titers of 5.7-6.4\%, and two-hour post-stimulus glucose levels of 140-199 mg/dL are used to identify prediabetes. Behavioral lifestyle changes and medications are useful in preventing the progression of prediabetes to T2DM [1].

Future health problems can be prevented with early identification and treatment of prediabetes and T2DM. However, many individuals with metabolic disorders remain undiagnosed, which can be attributed in part to the knowledge and clinical practices of primary care physicians (PCPs). Through the detection and management of prediabetes, PCPs play a crucial role in diabetes prevention. Understanding the level of 
PCPs' knowledge concerning prediabetes is key for successful screening initiatives and the commencement of suitable management interventions [5,6]. However, little is known about PCPs' knowledge either in Saudi Arabia or globally [7].

Most patients with prediabetes do not receive evidence-based preventive care from their PCPs [8,9]. Systemic barriers hinder physicians' ability to provide the best evidence-based practice, such as performance measures, insurance reimbursement, cultural expectations, and a lack of tools and staffing resources [10].

In a study conducted in the Al-Hassa region of Saudi Arabia in 2010, PCPs had substantial gaps in their knowledge regarding screening, diagnosing, and managing prediabetes [11]. Another study performed in 2020 in the Al-Qassim region reported that PCPs' knowledge, attitudes, and practices were suboptimal [12]. To date, no national study on this topic has been published in Saudi Arabia; however, surveys from the United States have exposed the limited awareness among PCPs regarding the risk factors that should be screened to detect prediabetes, the diagnostic laboratory parameters for this condition, and management guidelines once prediabetes is recognized $[6,7]$.

This study aims to close the knowledge gap regarding PCPs' screening and treatment practices for prediabetes in Saudi Arabia.

\section{Materials And Methods Study design and settings}

This was a cross-sectional study. PCPs living and practicing in Saudi Arabia were eligible for inclusion in the study. PCPs were invited using email and social media, for example, Twitter or WhatsApp, to complete a modified validated online survey questionnaire via Google Forms. The original questionnaire was adapted from a similar study conducted in the United States [5].

\section{Study participants}

The study targeted PCPs in Saudi Arabia who were invited to access the study questionnaire link and respond to its items. The link was shared over their social media platforms, including email, WhatsApp, Twitter, etc. No incentive was offered to the participants.

\section{Data collection and study instruments}

A modified validated questionnaire was employed [5], and the responses were collected via Google Forms. The questionnaire was open for responses between May 1, 2021, to June 25, 2021. The questionnaire is provided in the Appendix section. The questionnaire included items regarding participants' demographics, specialty, training, organization, knowledge about diabetes risk factors, diabetic and prediabetic fasting glucose (mg/dL), HbA1c (\%) diagnostic cut-off, minimum weight loss, physical activity for prediabetics, and guidelines for diabetes screening. Items on knowledge, practice, and beliefs regarding prediabetes management were assessed. The questionnaire also included items about participants' opinions regarding the importance of identifying prediabetes in their patients, at risk of developing diabetes, use of lifestyle modifications and metformin to reduce diabetes risk, barriers to lifestyle modification for patients with prediabetes, interventions to improve management and treatment of prediabetes, barriers to the adoption of the ADA guidelines, and suggestions regarding using metformin in patients with prediabetes. Additionally, we assessed participants' responses to prescribing metformin for patients with prediabetes and if the ADA guidelines for patients with prediabetes helped manage patients with prediabetes.

\section{Data analysis}

The data were entered, organized, tabulated, and analyzed using SPSS Statistics for Windows, version 26.0 (IBM Corp., Armonk, NY, USA). Demographic and socioeconomic data were tabulated and expressed as the frequency and percentage of the total participants. We used tables to report participant responses to survey questions as the frequency and percentage of the total participants. Figures illustrate the frequency distribution of the different variables.

\section{Ethical consideration}

Ethical approval for the study was obtained from the Research Ethics Committee of the University of Jeddah. The questionnaire was approved and validated by experts before it was sent to the PCPs. Data from the research were used only for research purposes. Consent was obtained from participants who agreed to provide their responses for use in our research. We did not collect or store any identifiable data.

\section{Results}

In total, 155 PCPs responded to the online survey. The participants' demographics, specialty, training, and work organization are listed in Table 1 . Overall, $51 \%$ of the participants were males, $98.7 \%$ were Saudi, $18.7 \%$ were from Riyadh city, and $81.3 \%$ specialized in family medicine. Most of the participants (71.9\%) were 


\section{Cureus}

residents; $64.5 \%$ worked for the Ministry of Health and $93.5 \%$ had completed part of their postgraduate training in Saudi Arabia.

\begin{tabular}{|c|c|}
\hline Variable & Number (\%) \\
\hline \multicolumn{2}{|l|}{ Gender } \\
\hline Male & 76 (49) \\
\hline Female & $79(51)$ \\
\hline \multicolumn{2}{|l|}{ Nationality } \\
\hline Non-Saudi & $2(1.3)$ \\
\hline Saudi & $153(98.7)$ \\
\hline \multicolumn{2}{|l|}{ City } \\
\hline Al Jouf & $3(1.9)$ \\
\hline Al Bahah & $1(0.6)$ \\
\hline Al Madinah & $16(10.3)$ \\
\hline Al-Ahsa & $3(1.9)$ \\
\hline Aseer & $12(7.7)$ \\
\hline Dammam & $14(9)$ \\
\hline Hafar Albatin & $1(0.6)$ \\
\hline Hail & $3(1.9)$ \\
\hline Jazan & $14(9)$ \\
\hline Jeddah & $25(16.1)$ \\
\hline Makkah & $14(9)$ \\
\hline Najran & $1(0.6)$ \\
\hline Northern & $2(1.3)$ \\
\hline Qassim & $4(2.6)$ \\
\hline Qatif & $1(0.6)$ \\
\hline Riyadh & $29(18.7)$ \\
\hline Tabuk & $7(4.5)$ \\
\hline Taif & $5(3.2)$ \\
\hline \multicolumn{2}{|l|}{ Specialty } \\
\hline Family medicine & $126(81.3)$ \\
\hline General practitioner (without advanced training) & $15(9.7)$ \\
\hline Internal medicine & $11(7.1)$ \\
\hline Obstetrics/gynecology & $3(1.9)$ \\
\hline \multicolumn{2}{|l|}{ Current level of training } \\
\hline Consultant & $7(4.5)$ \\
\hline General practitioner (without advanced training) & $14(9)$ \\
\hline Resident & $113(71.9)$ \\
\hline Specialist & 21 (13.5) \\
\hline
\end{tabular}




\section{Cureus}

\begin{tabular}{|c|c|}
\hline Military & $9(5.8)$ \\
\hline Ministry of Health & $100(64.5)$ \\
\hline Ministry of Health, Military & $3(1.9)$ \\
\hline Ministry of Health, Private & $2(1.3)$ \\
\hline National Guard & $9(5.8)$ \\
\hline National Guard, Military & $1(0.6)$ \\
\hline Private & $4(2.6)$ \\
\hline University & $20(12.9)$ \\
\hline University, Military & $1(0.6)$ \\
\hline University, Ministry of Health & $5(3.2)$ \\
\hline University, Private & $1(0.6)$ \\
\hline \multicolumn{2}{|c|}{ Country/countries where you did any level of your postgraduate training } \\
\hline Canada & $2(1.3)$ \\
\hline Saudi Arabia & $145(93.5)$ \\
\hline Saudi Arabia, Canada & $1(0.6)$ \\
\hline Saudi Arabia, United States & $3(1.9)$ \\
\hline Saudi Arabia, United States, Canada, United Kingdom & $1(0.6)$ \\
\hline Saudi Arabia, United States, United Kingdom, Germany & $1(0.6)$ \\
\hline United States & $1(0.6)$ \\
\hline United States, Canada & $1(0.6)$ \\
\hline
\end{tabular}

TABLE 1: Distribution of surveyed participants according to their demographics, specialty, training, and work organization $(n=155)$.

Participants were asked to identify diabetes risk factors. A history of gestational diabetes (92.2\%), a family history of diabetes in a first-degree relative (85.1\%), and a sedentary lifestyle (81.9\%) were the most commonly known risk factors (Figure 1). Only $27.7 \%$ of the study participants were aware of all nine risk factors for T2DM mentioned in the survey. 


\section{Cureus}

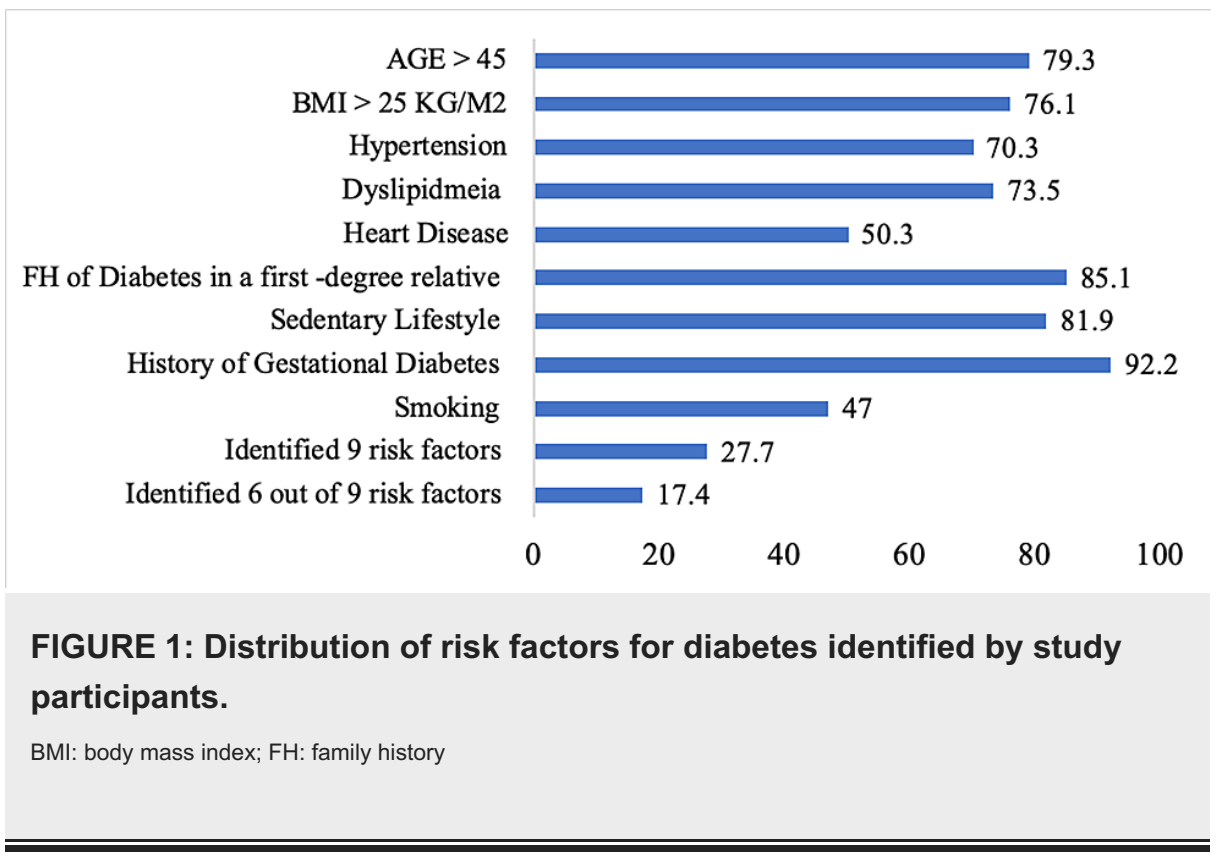

Regarding the diagnosis of diabetes, $74.8 \%$ and $60 \%$ of the participants were aware of the lower limits of fasting glucose $(126 \mathrm{mg} / \mathrm{dL}$ ) and HbA1c (6.5\%), respectively. Moreover, $60 \%$ and $68 \%$ were able to identify the lower $(100 \mathrm{mg} / \mathrm{dL})$ and upper $(125 \mathrm{mg} / \mathrm{dL})$ limits, respectively, of fasting glucose for the diagnosis of prediabetes, respectively. Additionally, $51 \%$ and $60.6 \%$ could correctly identify the lower (5.7\%) and upper (6.4\%) limits of HbA1c, respectively, for the diagnosis of prediabetes (Figure 2). Overall, 55.5\% of the participants identified the correct range of fasting glucose (100-125 mg/dL), and $43.6 \%$ were aware of the range of HbA1c levels (5.7-6.4\%) for diagnosing prediabetes (Figure 3).

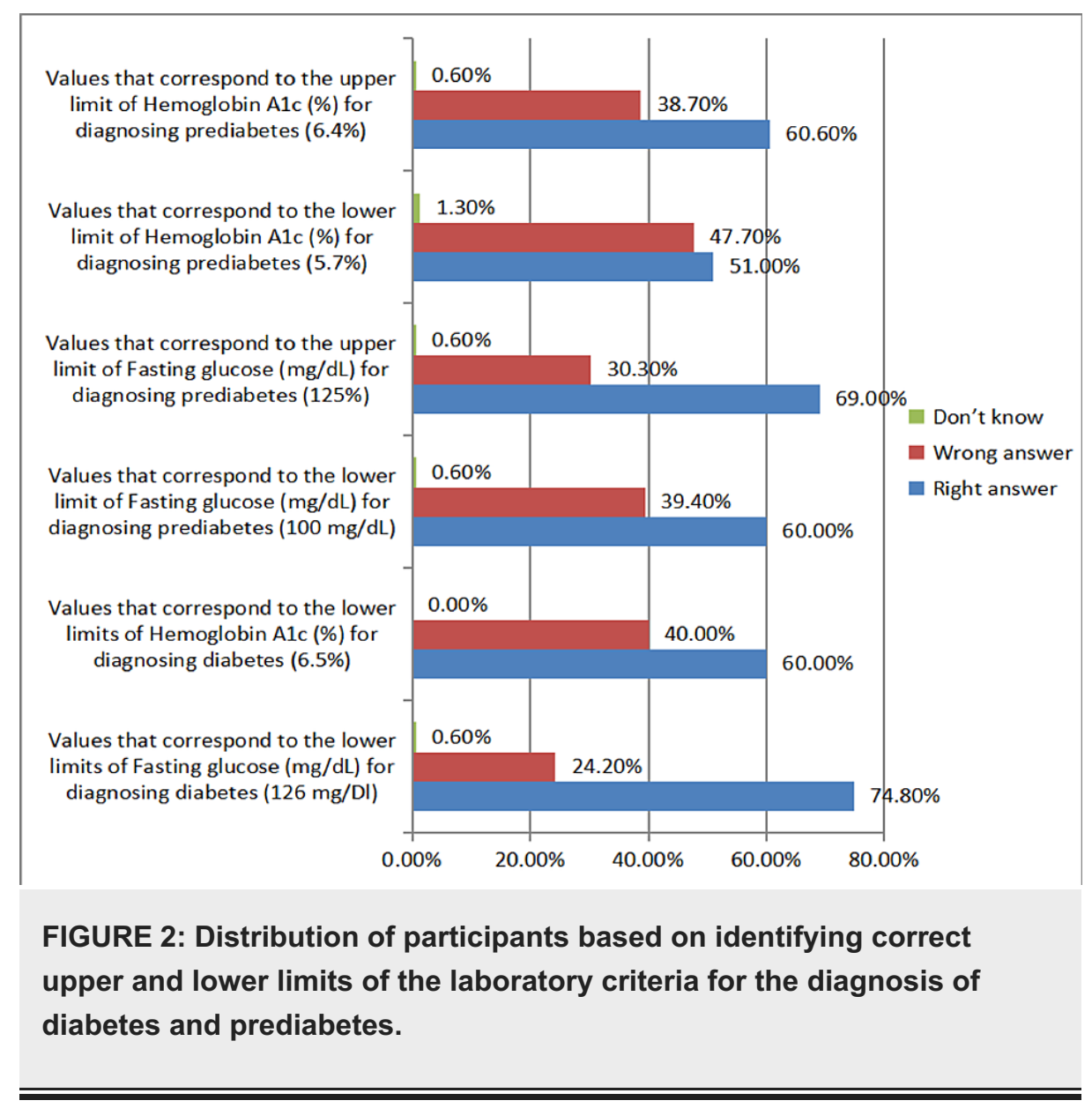




\section{Cureus}

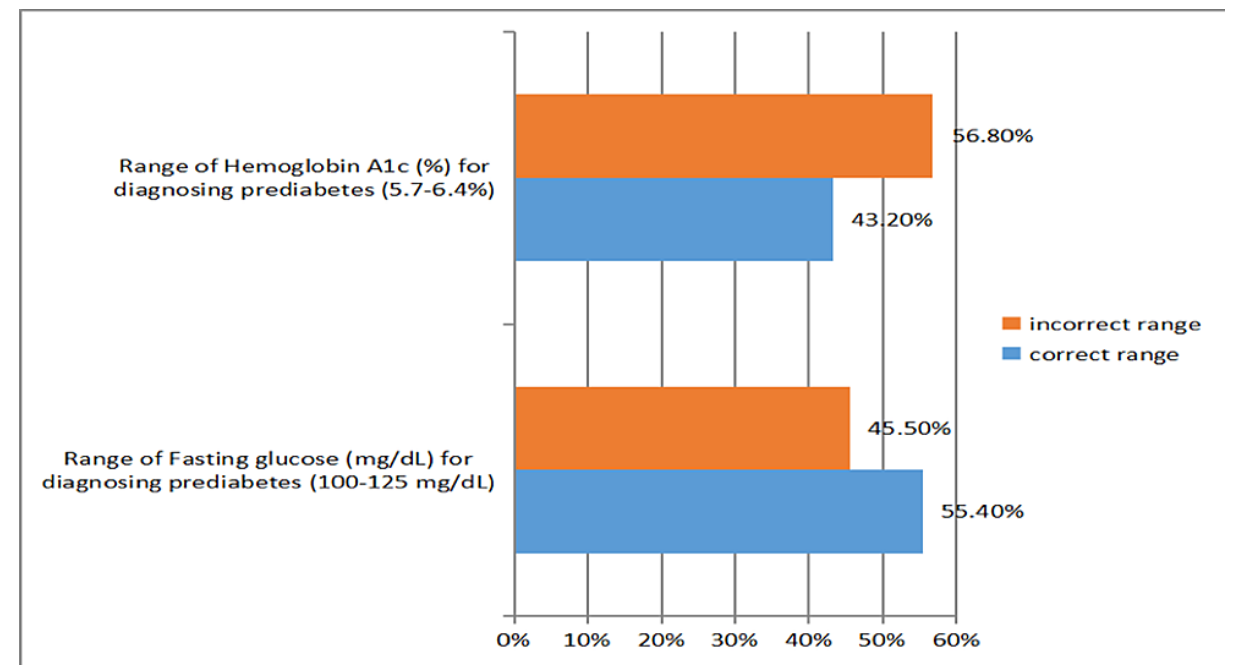

FIGURE 3: Percentage distribution of participants who were able to identify the correct ranges for fasting glucose and hemoglobin A1c for the diagnosis of prediabetes.

The most frequently performed tests to screen for prediabetes in at-risk populations were fasting blood glucose (85.8\%) and HbA1c (80.6\%). In total, 25.1\% used a two-hour oral glucose tolerance test, $24.5 \%$ utilized non-fasting blood glucose, and $1.9 \%$ did not routinely screen for diabetes. Only $33.5 \%$ of the participants were aware of the recommended minimum weight loss ( $5 \%$ of body weight) according to the ADA guidelines for patients with prediabetes. Overall, 56.1\% had precise knowledge of the ADA-

recommended minimum physical activity (150 minutes per week) for patients with prediabetes. The majority of participants (85.2\%) used the ADA guidelines for diabetes screening (Table 2).

\section{Variable}

Test(s) you order to screen for diabetes in at-risk populations in your practice (Select ALL that apply)

Non-fasting blood glucose

Fasting blood glucose

Hemoglobin A1c

Two-hour oral glucose tolerance test

I do not routinely screen for diabetes

Values that correspond to the lower limits of the laboratory criteria for diagnosing diabetes

Mentioned the right range $(100-125 \mathrm{mg} / \mathrm{dL})$

True

False

Values that correspond to the lower limit of hemoglobin A1c (\%) for diagnosing prediabetes

Correct answer (5.7\%)

Wrong answer

Don't know

Values that correspond to the upper limit of hemoglobin A1c (\%) for diagnosing prediabetes

Correct answer (6.4\%)

Wrong answer

Don't know

Mentioned the right range (5.7-6.4\%) 


\section{Cureus}

True

$67(43.2)$

False

$88(56.8)$

Values that correspond to ADA recommendations for minimum weight loss (\% of body weight) for patients with prediabetes

Correct answer (5\%)

Wrong answer

$76(49)$

Don't know

27 (17.4)

Values that correspond to ADA recommendations for minimum physical activity (minutes per week) for patients with prediabetes

Correct answer (150)

Wrong answer

66 (42.6)

Don't know

Guidelines, if any, you use for diabetes screening

ADA

American Association of Clinical Endocrinologists

American Diabetes Association

US Task Force for Preventive Services

None

TABLE 2: Distribution of studied participants according to their response to test(s) ordered to screen for diabetes in at-risk populations, minimum weight loss, physical activity for prediabetics, and use of guidelines for diabetes screening.

ADA: American Diabetes Association

Of the study participants, $69.7 \%, 45.8 \%$, and $52.9 \%$ strongly agreed that identifying prediabetes in their patients was important to manage health, to determine whether they needed to treat comorbid conditions, and to establish if elevated blood sugar levels required management, respectively (Table 3). In total, 40\% strongly agreed that patients with prediabetes progress to diabetes more quickly than those with normoglycemia. Moreover, $65.8 \%$ and $43.9 \%$ strongly agreed that lifestyle modification or metformin, respectively, could reduce the risk of diabetes in patients with prediabetes. 


\section{Cureus}

\begin{tabular}{|c|c|c|c|c|c|}
\hline & $\begin{array}{l}\text { Strongly } \\
\text { disagree }\end{array}$ & Disagree & Neutral & Agree & $\begin{array}{l}\text { Strongly } \\
\text { agree }\end{array}$ \\
\hline \multicolumn{6}{|l|}{ Identifying prediabetes in my patients is: } \\
\hline Important for managing their health & $4(2.6)$ & $5(3.2)$ & $10(6.5)$ & $\begin{array}{l}28 \\
(18.1)\end{array}$ & $\begin{array}{l}108 \\
(69.7)\end{array}$ \\
\hline $\begin{array}{l}\text { Helps me determine if I need to treat comorbid conditions, such as } \\
\text { hypertension, more aggressively }\end{array}$ & $5(3.2)$ & $12(7.7)$ & $\begin{array}{l}25 \\
(16.1)\end{array}$ & $\begin{array}{l}42 \\
(27.1)\end{array}$ & $71(45.8)$ \\
\hline Helps me determine if I need to treat elevated blood sugar levels & $6(3.9)$ & $6(3.9)$ & $\begin{array}{l}21 \\
(13.5)\end{array}$ & $\begin{array}{l}40 \\
(25.8)\end{array}$ & $82(52.9)$ \\
\hline $\begin{array}{l}\text { Patients with prediabetes progress to diabetes more quickly than those with } \\
\text { normoglycemia }\end{array}$ & $6(3.9)$ & $4(2.6)$ & $\begin{array}{l}25 \\
(16.1)\end{array}$ & $\begin{array}{l}58 \\
(37.4)\end{array}$ & $62(40)$ \\
\hline $\begin{array}{l}\text { Lifestyle modification can reduce the risk of diabetes in my patients with } \\
\text { prediabetes }\end{array}$ & $5(3.2)$ & $5(3.2)$ & $11(7.1)$ & $\begin{array}{l}32 \\
(20.6)\end{array}$ & $\begin{array}{l}102 \\
(65.8)\end{array}$ \\
\hline Metformin can reduce the risk of diabetes in my patients with prediabetes & $6(3.9)$ & $8(5.2)$ & $\begin{array}{l}25 \\
(16.1)\end{array}$ & $\begin{array}{l}48 \\
(31)\end{array}$ & $68(43.9)$ \\
\hline
\end{tabular}

TABLE 3: Participants' opinions regarding the importance of identifying prediabetes in their patients, the condition representing a risk for the development of diabetes, and the use of lifestyle modifications and metformin to reduce the risk of diabetes.

Regarding the initial management approach to prediabetes, $89 \%$ of the participants were able to identify that counseling patients on diet changes and physical activity to lose weight is the recommended initial management (Table 4). Additionally, 98.1\% repeated the laboratory tests within a year in an individual recognized as having prediabetes; $49.7 \%$ saw the patient for follow-up after three months. 


\section{Cureus}

\section{Variable}

Number (\%)

The best (recommended) initial management approach to a patient with prediabetes

Discuss starting the patient on metformin

Provide counseling on diet changes and physical activity to lose weight (right answer)

Refer the patient for bariatric surgery

Refer the patient to a behavioral weight loss program

Your initial management approach to a patient with prediabetes in your practice and with your current resources (Select ALL that apply)

I do not consider prediabetes a condition that requires specific management

Provide counseling on diet changes and physical activity to lose weight

Refer the patient to a nutritionist

Refer the patient to a behavioral weight loss program

Discuss starting the patient on metformin

Refer the patient for bariatric surgery

In a patient of yours that you diagnose with prediabetes, when, if at all, you have him/her repeat lab work

Three months

Six months

No specific recommendation

One year (right answer)

Two years

In a patient of yours with prediabetes, when, if at all, you have him/her return for follow-up in your clinic

Three months

Six months

No specific recommendation

One year

Two years

TABLE 4: Distribution of participants' knowledge, practice, and beliefs regarding prediabetes management.

There was an overall consensus that the barriers to lifestyle modification for individuals with prediabetes included patients' lack of motivation (80\%), physical limitations in doing an activity (71\%), and lack of weight loss resources (61.9\%). The most agreed interventions to improve management and treatment of prediabetes were improved access to diabetes prevention programs (82.5\%) and more educational $(80 \%)$ and improved nutrition (78.1\%) resources for patients (Table 5). 


\section{Cureus}

\begin{tabular}{|c|c|c|c|c|c|}
\hline Variable & $\begin{array}{l}\text { Strongly } \\
\text { disagree }\end{array}$ & Disagree & Neutral & Agree & $\begin{array}{l}\text { Strongly } \\
\text { agree }\end{array}$ \\
\hline \multicolumn{6}{|l|}{ Barriers to lifestyle modification for their patients with prediabetes } \\
\hline Patients' lack of motivation & $5(3.2)$ & $2(1.3)$ & $\begin{array}{l}24 \\
(15.5)\end{array}$ & $\begin{array}{l}69 \\
(44.5)\end{array}$ & $55(35.5)$ \\
\hline Patients' physical limitations in doing activity & $5(3.2)$ & $10(6.5)$ & $\begin{array}{l}30 \\
(19.4)\end{array}$ & $\begin{array}{l}68 \\
(43.9)\end{array}$ & $42(27.1)$ \\
\hline Lack of weight loss resources for patients & $8(5.2)$ & $19(12.3)$ & $\begin{array}{l}32 \\
(20.6)\end{array}$ & $\begin{array}{l}64 \\
(41.3)\end{array}$ & $32(20.6)$ \\
\hline Lack of nutrition resources for patients & $7(4.5)$ & $18(11.6)$ & $\begin{array}{l}37 \\
(23.9)\end{array}$ & $\begin{array}{l}56 \\
(36.1)\end{array}$ & $37(23.9)$ \\
\hline Patients do not think it is important to make these changes & $6(3.9)$ & $8(5.2)$ & $\begin{array}{l}4 \\
(26.5)\end{array}$ & $\begin{array}{l}48 \\
(31)\end{array}$ & $52(33.5)$ \\
\hline Financial Iımıtatıons & $21(13.5)$ & $19(12.3)$ & $45(29)$ & $\begin{array}{l}49 \\
(31.6)\end{array}$ & $21(13.5)$ \\
\hline \multicolumn{6}{|l|}{ Interventions to improve management and treatment of prediabetes } \\
\hline More time for doctors to counsel patients & $5(3.2)$ & $2(1.3)$ & $\begin{array}{l}42 \\
(27.1)\end{array}$ & $\begin{array}{l}61 \\
(39.4)\end{array}$ & $45(29)$ \\
\hline More educational resources for patients & $1(0.6)$ & $5(3.2)$ & $\begin{array}{l}25 \\
(16.1)\end{array}$ & $\begin{array}{l}58 \\
(37.4)\end{array}$ & $66(42.6)$ \\
\hline $\begin{array}{l}\text { Improved access to diabetes prevention programs (an evidence-based } \\
\text { lifestyle change program) }\end{array}$ & $3(1.9)$ & $3(1.9)$ & $\begin{array}{l}21 \\
(13.5)\end{array}$ & $\begin{array}{l}63 \\
(40.6)\end{array}$ & $65(41.9)$ \\
\hline Improved nutrition resources for patients & $5(3.2)$ & $2(1.3)$ & $\begin{array}{l}27 \\
(17.4)\end{array}$ & $\begin{array}{l}62 \\
(40)\end{array}$ & $59(38.1)$ \\
\hline Improved access to weight loss programs & $2(1.3)$ & $6(3.9)$ & $\begin{array}{l}23 \\
(14.8)\end{array}$ & $\begin{array}{l}59 \\
(38.1)\end{array}$ & $65(41.9)$ \\
\hline Improved access to bariatric surgery & $7(4.5)$ & $13(8.4)$ & $\begin{array}{l}47 \\
(30.3)\end{array}$ & $\begin{array}{l}49 \\
(31.6)\end{array}$ & $39(25.2)$ \\
\hline
\end{tabular}

TABLE 5: Participants' opinions about barriers to lifestyle modification for their patients with prediabetes and interventions to improve management and treatment of prediabetes.

Metformin was prescribed in individuals with the following parameters: body mass index $\geqslant 35 \mathrm{~kg} / \mathrm{m}^{2}$ ( $72.2 \%$ ), lack of response to lifestyle intervention (56.7\%), history of gestational diabetes (44.5\%), and HbA1c $>6 \%$ (42.5\%). However, $13.5 \%$ inferred that they did not believe in a rule for the use of metformin in prediabetes. Overall, $63.9 \%$ and $11 \%$ stated that they prescribed metformin to $>5 \%$ and $>50 \%$ of their prediabetes patients, respectively. Further, $68.4 \%$ of the participants indicated that the ADA guidelines were useful for the management of patients with prediabetes (Table 6 ). 


\section{Cureus}

Variable

Number (\%)

Which of the following would make you more likely to prescribe metformin for a patient with prediabetes? (Select ALL that apply)

I don't believe in prescribing metformin for patients with prediabetes

BMI $\geq 35 \mathrm{~kg} / \mathrm{m}^{2}$

Family history of diabetes

Dyslipidemia

Hypertension

History of gestational diabetes

$\mathrm{HbA} 1 \mathrm{c}>6 \%$

History of heart disease

Age $<60$

Age $\geq 60$

Lack of response to lifestyle intervention

$88(56.7$

Of your patients with prediabetes (without progression to diabetes), for what percentage have you prescribed metformin? (Select ONE)

$>25-50 \%$

$>5-25 \%$

$>50-75 \%$

$>75 \%$

$1-5 \%$

Have the American Diabetes Association guidelines for patients with prediabetes been helpful in managing your patients with prediabetes? (Select ONE)

No, I'm familiar with them but they are not useful in my practice

No, I'm not familiar with them

Unsure

$28(18.1)$

Yes

$106(68.4)$

TABLE 6: Participants responses' to prescribing metformin for a patient with prediabetes and whether the American Diabetes Association guidelines for patients with prediabetes are helpful in managing patients with prediabetes.

Barriers identified by participants toward the adoption of the ADA guidelines suggesting using metformin in certain patients with prediabetes included patients preferring not to take medication (63.9\%), poor patient adherence (62.6\%), providers' lack of awareness of clinical guidelines for metformin (50.3\%), and potential side effects (49.1\%) (Table 7 ). 


\section{Cureus}

\begin{tabular}{|c|c|c|c|c|c|}
\hline Variable & $\begin{array}{l}\text { Strongly } \\
\text { disagree }\end{array}$ & Disagree & Neutral & Agree & $\begin{array}{l}\text { Strongly } \\
\text { agree }\end{array}$ \\
\hline Patients do not like taking medication & $4(2.6)$ & $6(3.9)$ & $\begin{array}{l}46 \\
(29.7)\end{array}$ & $\begin{array}{l}61 \\
(39.4)\end{array}$ & $38(24.5)$ \\
\hline Medication cost to patient & $19(12.3)$ & $44(28.4)$ & $\begin{array}{l}52 \\
(33.5)\end{array}$ & $\begin{array}{l}32 \\
(20.6)\end{array}$ & $8(5.2)$ \\
\hline Poor patient adherence & $4(2.6)$ & $8(5.2)$ & $\begin{array}{l}46 \\
(29.7)\end{array}$ & $\begin{array}{l}66 \\
(42.6)\end{array}$ & $31(20)$ \\
\hline Potential side effects & $4(2.6)$ & $17(11)$ & $\begin{array}{l}58 \\
(37.4)\end{array}$ & $\begin{array}{l}57 \\
(36.8)\end{array}$ & $19(12.3)$ \\
\hline Providers' lack of awareness of clinical guidelines for metformin use & $5(3.2)$ & $18(11.6)$ & $\begin{array}{l}54 \\
(34.8)\end{array}$ & $\begin{array}{l}63 \\
(40.6)\end{array}$ & $15(9.7)$ \\
\hline $\begin{array}{l}\text { Lack of Food and Drug Administration approval for metformin use in } \\
\text { prediabetes }\end{array}$ & $18(11.6)$ & $42(27.1)$ & $\begin{array}{l}58 \\
(37.4)\end{array}$ & $31(20)$ & $6(3.9)$ \\
\hline
\end{tabular}

TABLE 7: Participants' opinions about barriers to the adoption of the ADA guidelines which recommend using metformin in certain patients with prediabetes.

\section{Discussion}

This study was designed to evaluate prediabetes screening and treatment practices among PCPs and is the first national survey to address this subject in Saudi Arabia. This work has facilitated the recognition of gaps in PCPs' knowledge regarding prediabetes which need to be addressed. Because patients with prediabetes have an increased risk of cardiovascular disease and all-cause mortality, early management of prediabetes, which includes the screening of eligible patients and interventions to prevent its progression to T2DM, is crucial $[1,2]$.

There was a gap in participants' knowledge of the risk factors for prediabetes; only $27.7 \%$ of the participants were aware of the nine risk factors included in the survey. There was also a gap in the recognition of the diagnostic cut-off for prediabetes because only $55.5 \%$ and $43.6 \%$ of the participants were aware of the fasting glucose (100-125 mg/dL) and HbA1c (5.7-6.4\%) ranges, respectively. Some PCPs (24.5\%) utilized nonfasting blood glucose to screen for diabetes, which is neither a parameter recommended by the ADA nor a component of the diagnostic criteria for prediabetes. This can lead to underscreening of eligible patients and underdiagnosis of prediabetes. Extensive national data regarding prediabetes is lacking in Saudi Arabia. However, in other countries, for example, the United States, the majority of individuals with prediabetes are not aware of their condition, a scenario potentially attributed to PCPs' lack of knowledge of the diagnostic criteria [6].

This study also demonstrated a knowledge gap regarding the implementation of preventive measures. For instance, only $33.5 \%$ and $56.1 \%$ of PCPs were aware of the recommended ADA goals for minimum weight loss and physical activity, respectively, for patients with prediabetes. The knowledge of these parameters is important because these are evidence-based recommendations based on multiple studies that have demonstrated that lifestyle modifications successfully improved cardiometabolic markers and prevented progression from prediabetes to T2DM [1].

In other countries, PCPs reported barriers to prediabetes treatment related to the patients $[8,13,14]$. In this study, most of the PCPs described the following lifestyle modification barriers for their patients with prediabetes: physical limitations, poor motivation, lack of resources for nutrition and weight loss, and patients' beliefs that lifestyle changes are not important. An approach that could be used to encourage individuals' uptake of lifestyle modification is through counseling sessions with PCPs. This approach has been reported to be effective and engaging in changing patients' perceptions toward lifestyle modifications [15-17].

Studies have shown that a very low proportion of patients with prediabetes take metformin $[8,18]$. Nevertheless, a previous survey of patients showed that the majority believe that lifestyle modification alone, metformin alone, or lifestyle modification combined with metformin are valid treatments for prediabetes [19]. Thus, many apparent barriers to the adoption of the ADA guidelines regarding the use of metformin reported by PCPs in some individuals with prediabetes in this study might be false. The data from this survey showed that in Saudi Arabia, PCPs prescribe metformin for less than half of their patients with prediabetes. 
Suggested interventions that could improve the management and treatment of prediabetes reported by PCPs were similar to those published in studies from other countries, such as improved patient access to diabetes prevention programs, educational resources, and nutritional resources [6,7].

This study has multiple strengths. It is the first national survey in Saudi Arabia to evaluate PCPs' knowledge and practices concerning prediabetes. Responses were received from PCPs from the majority of the principal territories within Saudi Arabia and a spectrum of practice types. Limitations of this study include the possibility of recall and social desirability bias. Another important limitation is that most of the study participants were family medicine specialists and resident physicians, which could limit data generalizability to other specialties and other training levels. Moreover, the majority of respondents were Saudi, limiting the generalizability of the findings to non-Saudi PCPs who constitute a large portion of PCPs in Saudi Arabia.

\title{
Conclusions
}

This national survey uncovered important gaps in PCPs' knowledge regarding prediabetes in Saudi Arabia, which can contribute to both underscreening and undertreating prediabetes. The identification of these gaps is essential to focus educational endeavors toward PCPs who act as first-line healthcare providers and screen for and manage prediabetes and diabetes. Addressing their knowledge gaps can have a substitutional effect on the fight against diabetes.

\section{Appendices}

\section{The survey used in this study}

Part I. The following questions apply to your knowledge and practices regarding diabetes screening.

1. Which of the following are risk factors that might prompt you to screen for diabetes? (Select ALL that apply)

\author{
Age $\geqslant 45$ \\ BMI $\geqslant 25 \mathrm{~kg} / \mathrm{m} 2$ \\ Hypertension \\ Dyslipidemia \\ Heart disease \\ Family history of diabetes in a first-degree relative \\ Sedentary lifestyle \\ History of gestational diabetes \\ Smoking
}

2. In your practice, which test(s) do you order to screen for diabetes in at-risk populations? (Select ALL that apply)

Non-fasting blood glucose

Fasting blood glucose

Hemoglobin A1c

Two-hour oral glucose tolerance test

I do not routinely screen for diabetes

3. Please circle the values that correspond to the lower limits of the lab criteria for diagnosing diabetes.

a. Fasting glucose (mg/dL):

Don’t know

100102104106108110112114116118120122124126128130132134136138140 


\section{Cureus}

b. Hemoglobin A1c (\%): Don’t know

$\begin{array}{lllllllllllllllllllll}5.0 & 5.1 & 5.2 & 5.3 & 5.4 & 5.5 & 5.6 & 5.7 & 5.8 & 5.9 & 6.0 & 6.1 & 6.2 & 6.3 & 6.4 & 6.5 & 6.6 & 6.7 & 6.8 & 6.9 & 7.0\end{array}$

4. Please circle the values that correspond to the upper and lower limits (range) of the laboratory criteria for diagnosing prediabetes.

a. Fasting glucose $(\mathrm{mg} / \mathrm{dL})$ Don’t know

$\begin{array}{lllllllllllllllllll}70 & 75 & 80 & 85 & 90 & 95 & 100 & 105 & 110 & 115 & 120 & 125 & 130 & 135 & 140 & 145 & 150 & 155 & 160\end{array}$

b. Hemoglobin A1c (\%): Don't know

$\begin{array}{lllllllllllllllllllll}5.0 & 5.1 & 5.2 & 5.3 & 5.4 & 5.5 & 5.6 & 5.7 & 5.8 & 5.9 & 6.0 & 6.1 & 6.2 & 6.3 & 6.4 & 6.5 & 6.6 & 6.7 & 6.8 & 6.9 & 7.0\end{array}$

5. Please circle the value that corresponds to ADA recommendations for lifestyle modification for patients with prediabetes:

a. Minimum weight loss (\% of body weight): Don’t know

$\begin{array}{llllllllllllllllllll}1 & 2 & 3 & 4 & 5 & 6 & 7 & 8 & 9 & 10 & 11 & 12 & 13 & 14 & 15 & 16 & 17 & 18 & 19 & 20\end{array}$

b. Minimum physical activity (minutes per week): Don't know

$\begin{array}{llllllllllllllllllll}10 & 20 & 30 & 40 & 50 & 60 & 70 & 80 & 90 & 100 & 110 & 120 & 130 & 140 & 150 & 160 & 170 & 180 & 190 & 200\end{array}$

6. Which guidelines, if any, do you use for diabetes screening? (Select ONE)

None

American Diabetes Association

US Task Force for Preventive Services

American Association of Clinical Endocrinologists

Other

How strongly do you agree or disagree with the following statements?

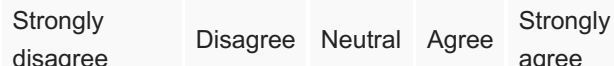

7. Identifying prediabetes in my patients is:

a. Important for managing their health

b. Helps me determine if I need to treat comorbid conditions such as hypertension more aggressively

c. Helps me determine if I need to treat elevated blood sugars

8. Patients with prediabetes progress to diabetes more quickly than those with normoglycemia

9. Lifestyle modification can reduce the risk of diabetes in my patients with prediabetes

10. Metformin can reduce the risk of diabetes in my patients with prediabetes

$\begin{array}{lllll}\square & \square & \square & \square & \square \\ \square & \square & \square & \square & \square \\ \square & \square & \square & \square & \square \\ \square & \square & \square & \square & \square \\ \square & \square & \square & \square & \square \\ \square & \square & \square & \\ \square & \square & \square & \square\end{array}$

TABLE 8: Questions 7-10 of the survey.

Part II. The following questions apply to your knowledge, practices, and beliefs regarding prediabetes management. 


\section{Cureus}

1. Which of the following is the best (recommended) initial management approach to a patient with prediabetes? (Select ONE)

Provide counseling on diet changes and physical activity to lose weight

Refer the patient to a behavioral weight loss program

Discuss starting the patient on metformin

Refer the patient for bariatric surgery

Other

2. In your practice and with your current resources, what is your initial management approach to a patient with prediabetes? (Select ALL that apply)

I do not consider prediabetes a condition that requires specific management

Provide counseling on diet changes and physical activity to lose weight

Refer the patient to a nutritionist

Refer the patient to a behavioral weight loss program

Discuss starting the patient on metformin

Refer the patient for bariatric surgery

Other

3. In a patient of yours that you diagnose with prediabetes, when, if at all, would you have him/her repeat lab work? (Select ONE)

3 months

6 months

One year

Two years

No specific recommendation

Other

4. In a patient of yours with prediabetes, when, if at all, would you have him/her return for follow up in your clinic? (Select ONE)

3 months

6 months

One year

Two years

No specific recommendation

Other 


\section{Cureus}

15. How strongly do you agree or disagree that the following are barriers to lifestyle modification for your patients with prediabetes?

Strongly disagree Disagree Neutral Agree Strongly agree

Patient's lack of motivation

Patient's physical limitations in doing an activity

Lack of weight loss resources for patient

Lack of nutrition resources for patient

Patients don't think it is important to make these changes

\begin{tabular}{|c|c|c|c|c|}
\hline$\square$ & $\square$ & $\square$ & $\square$ & $\square$ \\
\hline$\square$ & $\square$ & 口 & $\square$ & $\square$ \\
\hline$\square$ & $\square$ & $\square$ & $\square$ & $\square$ \\
\hline$\square$ & $\square$ & $\square$ & $\square$ & $\square$ \\
\hline$\square$ & $\square$ & 口 & $\square$ & $\square$ \\
\hline 口 & $\square$ & 口 & $\square$ & $\square$ \\
\hline
\end{tabular}

Financial limitations

16. How strongly do you feel that these interventions will improve the management and treatment of prediabetes?

\begin{tabular}{|c|c|c|c|c|c|}
\hline & $\begin{array}{l}\text { Strongly } \\
\text { disagree }\end{array}$ & Disagree & Neutral & Agree & $\begin{array}{l}\text { Strongly } \\
\text { agree }\end{array}$ \\
\hline More time for doctors to counsel patients & $\square$ & $\square$ & $\square$ & $\square$ & $\square$ \\
\hline More educational resources for patients & $\square$ & $\square$ & $\square$ & $\square$ & $\square$ \\
\hline $\begin{array}{l}\text { Improved access to diabetes prevention programs (an evidence-based lifestyle } \\
\text { change program) }\end{array}$ & $\square$ & $\square$ & $\square$ & $\square$ & $\square$ \\
\hline Improved nutrition resources for patients & $\square$ & $\square$ & $\square$ & $\square$ & $\square$ \\
\hline Improved access to weight loss programs & $\square$ & $\square$ & $\square$ & $\square$ & $\square$ \\
\hline Improved access to bariatric surgery & 口 & $\square$ & $\square$ & $\square$ & $\square$ \\
\hline
\end{tabular}

TABLE 9: Questions 15 and 16 of the survey.

Part III. The following questions apply to your knowledge, practices, and beliefs regarding the treatment of prediabetes with medication.

17. Which of the following would make you more likely to prescribe metformin for a patient with prediabetes? (Select ALL that apply)

I don't believe in prescribing metformin for patients with prediabetes

$\mathrm{BMI} \geqslant 35 \mathrm{~kg} / \mathrm{m} 2$

Family history of diabetes

Dyslipidemia

Hypertension

History of gestational diabetes

$\mathrm{HbA} 1 \mathrm{c}>6 \%$

History of heart disease

Age $<60$

Age $\geqslant 60$

Lack of response to lifestyle intervention

Other 


\section{Cureus}

18. Of your patients with prediabetes (without progression to diabetes), for what percentage of them have you prescribed metformin? (Select ONE)

$$
\begin{aligned}
& 0 \% \\
& 1-5 \% \\
& >5-25 \% \\
& >25-50 \% \\
& >50-75 \% \\
& >75 \%
\end{aligned}
$$

19. Have the American Diabetes Association guidelines for patients with prediabetes been helpful in managing your patients with prediabetes? (Select ONE)

Yes

No, I'm not familiar with them

No, I'm familiar with them but they are not useful in my practice

Unsure

20. The ADA guidelines suggest using metformin in certain patients with prediabetes. Studies suggest that few patients are prescribed metformin for prediabetes. How strongly do you agree or disagree that the following are barriers to adoption?

Patients do not like taking medications

Medication cost to patients

Poor patient adherence

Potential side effects

Providers' lack of awareness of clinical guidelines for metformin use

Lack of FDA approval for metformin use in prediabetes

Other reason:

$\begin{array}{lllll}\text { Strongly disagree } & \text { Disagree } & \text { Neutral } & \text { Agree } & \text { Strongly agree } \\ \square & \square & \square & \square & \square \\ \square & \square & \square & \square & \square \\ \square & \square & \square & \square & \square \\ \square & \square & \square & \square & \square \\ \square & \square & \square & \square & \square \\ \square & \square & \square & \square & \square\end{array}$

\section{TABLE 10: Question 20 of the survey.}

Part IV. Demographic information

21. What is your gender?

Female

Male

22. What is your nationality?

Saudi

Non-Saudi, please specify

23. What is your specialty? (Select ALL that apply)

Family Medicine 


\section{Cureus}

Internal Medicine

OB/Gyn

General practitioner (without advanced training)

Other

24. What is your current level of training?

Consultant

Specialist

Fellow

Resident

General practitioner (without advanced training)

25. Please select the type of organization you work with now (Select ALL that apply).

University

Ministry of health

National guard

Military

Private

Other

26. Please select the city of your current practice.

Jeddah

Riyadh

Dammam

Makkah

Al Madinah

Other

27. Please select country/countries where you did any level of your postgraduate training (Select ALL that apply.

Saudi Arabia

United States

Canada

United Kingdom

Germany

France

Egypt 
Other

\section{Additional Information Disclosures}

Human subjects: Consent was obtained or waived by all participants in this study. University of Jeddah Ethics Committee issued approval NA. Animal subjects: All authors have confirmed that this study did not involve animal subjects or tissue. Conflicts of interest: In compliance with the ICMJE uniform disclosure form, all authors declare the following: Payment/services info: All authors have declared that no financial support was received from any organization for the submitted work. Financial relationships: All authors have declared that they have no financial relationships at present or within the previous three years with any organizations that might have an interest in the submitted work. Other relationships: All authors have declared that there are no other relationships or activities that could appear to have influenced the submitted work.

\section{References}

1. 2. Classification and diagnosis of diabetes: standards of medical care in diabetes-2021. Diabetes Care. 2021, 44:S15-33. 10.2337/dc21-S002

2. Cai X, Zhang Y, Li M, et al.: Association between prediabetes and risk of all cause mortality and cardiovascular disease: updated meta-analysis. BMJ. 2020, 370:m2297. 10.1136/bmj.m2297

3. DeJesus RS, Breitkopf CR, Rutten LJ, Jacobson DJ, Wilson PM, Sauver JS: Incidence rate of prediabetes progression to diabetes: modeling an optimum target group for intervention. Popul Health Manag. 2017, 20:216-23. 10.1089/pop.2016.0067

4. Lin JD, Wan HL, Li JC, et al.: Impaired glucose tolerance and impaired fasting glucose share similar underlying pathophysiologies. Tohoku J Exp Med. 2007, 212:349-57. 10.1620/tjem.212.349

5. Tseng E, Greer RC, O'Rourke P, et al.: National survey of primary care physicians' knowledge, practices, and perceptions of prediabetes. J Gen Intern Med. 2019, 34:2475-81. 10.1007/s11606-019-05245-7

6. Tseng E, Greer RC, O'Rourke P, Yeh HC, McGuire MM, Clark JM, Maruthur NM: Survey of primary care providers' knowledge of screening for, diagnosing and managing prediabetes. J Gen Intern Med. 2017, 32:1172-8. 10.1007/s11606-017-4103-1

7. Hafez D, Nelson DB, Martin EG, Cohen AJ, Northway R, Kullgren JT: Understanding type 2 diabetes mellitus screening practices among primary care physicians: a qualitative chart-stimulated recall study. BMC Fam Pract. 2017, 18:50. 10.1186/s12875-017-0623-3

8. Schmittdiel JA, Adams SR, Segal J, et al.: Novel use and utility of integrated electronic health records to assess rates of prediabetes recognition and treatment: brief report from an integrated electronic health records pilot study. Diabetes Care. 2014, 37:565-8. 10.2337/dc13-1223

9. Moin T, Li J, Duru OK, et al.: Metformin prescription for insured adults with prediabetes from 2010 to 2012: a retrospective cohort study. Ann Intern Med. 2015, 162:542-8. 10.7326/M14-1773

10. Chan WV, Pearson TA, Bennett GC, et al.: ACC/AHA special report: clinical practice guideline implementation strategies: a summary of systematic reviews by the NHLBI Implementation Science Work Group: a report of the American College of Cardiology/American Heart Association Task Force on Clinical Practice Guidelines. Circulation. 2017, 135:e122-37. 10.1161/CIR.0000000000000481

11. Khan AR, Al Abdul Lateef ZN, Khamseen MB, Al Aithan MA, Khan SA, Al Ibrahim I: Knowledge, attitude and practice of ministry of health primary health care physicians in the management of type 2 diabetes mellitus: a cross-sectional study in the Al Hasa District of Saudi Arabia, 2010. Niger J Clin Pract. 2011, 14:52-9. 10.4103/1119-3077.79241

12. Alasqah AA, Aldosari FI, Almutaz AI: Primary care physicians' knowledge, attitudes, and practices related to diabetic retinopathy in Buraidah city, Qassim region, Saudi Arabia. Saudi J Health Sci. 2020, 9:152-9. 10.4103/sjhs.sjhs_46_20

13. Kandula NR, Moran MR, Tang JW, O'Brien MJ: Preventing diabetes in primary care: providers' perspectives about diagnosing and treating prediabetes. Clin Diabetes. 2018, 36:59-66. 10.2337/cd17-0049

14. Mainous AG 3rd, Tanner RJ, Baker R: Prediabetes diagnosis and treatment in primary care. J Am Board Fam Med. 2016, 29:283-5. 10.3122/jabfm.2016.02.150252

15. Jay M, Gillespie C, Schlair S, Sherman S, Kalet A: Physicians' use of the 5As in counseling obese patients: is the quality of counseling associated with patients' motivation and intention to lose weight?. BMC Health Serv Res. 2010, 10:159. 10.1186/1472-6963-10-159

16. Post RE, Mainous AG 3rd, Gregorie SH, Knoll ME, Diaz VA, Saxena SK: The influence of physician acknowledgment of patients' weight status on patient perceptions of overweight and obesity in the United States. Arch Intern Med. 2011, 171:316-21. 10.1001/archinternmed.2010.549

17. Rose SA, Poynter PS, Anderson JW, Noar SM, Conigliaro J: Physician weight loss advice and patient weight loss behavior change: a literature review and meta-analysis of survey data. Int J Obes (Lond). 2013, 37:11828. 10.1038/ijo.2012.24

18. Tseng E, Yeh HC, Maruthur NM: Metformin use in prediabetes among U.S. adults, 2005-2012 . Diabetes Care. 2017, 40:887-93. 10.2337/dc16-1509

19. O'Brien MJ, Moran MR, Tang JW, et al.: Patient perceptions about prediabetes and preferences for diabetes prevention. Diabetes Educ. 2016, 42:667-77. 10.1177/0145721716666678 